\title{
Vorbemerkung des Verlages
}

Der Text, den J. Hoffmeister 1930 als Jenenser Realphilosophie II. Die Vorlesungen von $1805 / 06$ veröffentlicht hat, wird hier als Nachdruck, jedoch unter verändertem Titel wieder vorgelegt. Der heutige Stand der Forschung erlaubt es nicht mehr, diesem Text als frühere Stufe eine „Realphilosophie I“ voranzustellen, wie Hoffmeister es 1931 getan hat. Für die kritische Ausgabe von G.W.F. Hegel, Gesammelte Werke, die im gleichen Verlag erscheinen wird, bereitet das Hegel-Archiv in Bonn z. Z. auch die Neuedition der Jenaer Schriften vor; die Vorarbeiten haben ergeben, daß Hegel nur im Wintersemester 1805/06 eine "philosophia realis" als gesonderte Darstellung der Philosophie der Natur und des Geistes, ohne die grundlegenden Teile des Systems der Philosophie (Logik und Metaphysik), angekündigt hat. Für diese Vorlesung ist die hier abgedruckte Niederschrift im Herbst 1805 entstanden. Als „philosophia naturae et mentis" erschien die Vorlesung dann vom Sommer 1806 bis zum Sommer 1807 in Hegels Ankündigungen, wurde aber wohl nur im Sommer 1806 aufgrund der Manuskripte des vorhergehenden Semesters gehalten.

Der Nachdruck soll den vielverlangten Text wieder für das Studium verfügbar machen. Ein Wiederabdruck der sogenannten "Jenenser Realphilosophie I“ erscheint dagegen sachlich nicht vertretbar. Es handelt sich dort nicht um eine gesonderte Darstellung der Natur- und Geistesphilosophie, sondern um Fragmente von Manuskripten zu der Vorlesung "philosophiae speculativae systema, complectens a) Logicam et Metaphysicam ... b) philosophiam naturae et c) mentis“ 
vom Wintersemester 1803/04. Diesen Sachverhalt hat Hoffmeister bei seiner verdienstlichen Erstveröffentlichung der Manuskripte nicht zur Geltung gebracht; vielmehr wurde er durch die Analogie zur Realphilosophie von 1805/06, die er zuerst herausgegeben hatte, zu der Konzeption einer „Realphilosophie I“ geführt. Für diesen Text wird man die bereits in Arbeit befindliche kritische Neuausgabe abwarten müssen.

Die vorstehenden Hinweise und die darin enthaltene Begründung für die Änderung des Titels dieses Bandes beruhen auf Mitteilungen, die der Verlag dem Hegel-Archiv verdankt.

Hamburg, im Juni 1967 